\title{
PRODUTOS DOS ESTUDOS DA PAISAGEM
}

\author{
Roseline Oliveira \\ Universidade Federal de Alagoas \\ roselineoliveira@gmail.com \\ Alice Jardim \\ Universidade Federal de Alagoas \\ alicejardim@gmail.com \\ Gustavo Baraldi \\ Universidade Federal de Alagoas \\ gustavobaraldi@gmail.com
}

\begin{abstract}
Resumo: Como eram as primeiras cidades brasileiras? Como elas surgiram? É possível reconhecer seu antigo patrimônio hoje? Como despertar memórias adormecidas no contexto contemporâneo desses lugares? A gênese da paisagem urbana nordestina e seus remanescentes consistem nos temas centrais dos trabalhos desenvolvidos pelo Grupo de Pesquisa Estudos da Paisagem (UFAL). Além das investigações de cunho acadêmico, que privilegiam o estudo da iconografia histórica e a experiência empírica, a intenção também é produzir documentação patrimonial, a qual conta com um acervo de cerca de 25 mil imagens, dentre elas, registros fotográficos e audiovisuais. Nos últimos anos, o Laboratório de Criação Taba-êtê - um subgrupo do Grupo de Pesquisa, formado por profissionais e estudantes de Arquitetura e Design, vem trabalhando na perspectiva de transformar suas ferramentas de investigação - viagens e imagens - em produtos, de maneira a retornar às comunidades estudadas o conhecimento que elas mesmas ajudaram a construir. Dentre essas criações situam-se exposições de cunho interativo, objetos ludos-didáticos, livros e instalações, cuja produção recebeu apoio de diversas instituições, tais como IPHAN, Banco do Nordeste do Brasil e Petrobrás, inclusive tendo um deles sido aprovado pela Lei Rouanet e recebido ainda a Chancela da UNESCO. A proposta deste artigo consiste, pois, em apresentar esses produtos de caráter artístico, enquanto representações dos estudos sobre o patrimônio paisagístico, essencialmente comprometidos com o conhecimento histórico-cultural e a prática educativa.
\end{abstract}

Palavras-chave: Cidades pós-coloniais, patrimônio paisagístico, Design. 
Abstract: What were the first towns in Brazil like? How did they arise? Is it possible to recognise their ancient heritage today? How can one awake the slumbering memories of these places in the contemporary world? The genesis of the urban landscape of the North-East of the country and its vestigial remains, form a significant part of the studies carried out by the Landscape Research Group. As well as these investigations of an academic nature, which highlight the study of historical iconography and empirical experience, the study also seeks to produce 'patrimonial documentation' which comprises a collection of about 25.000 images, including photographic and audiovisual records. In the last five years, the Taba-êtê Creation Laboratory - a subdivision of the Research Group made up of professionals and students in the area of Architecture and Design have been attempting to change their investigative tools (trips and images) into 'products'. This has been undertaken in a way that can allow the knowledge that the communities under study have helped to produce in the past, to be restored to them. Among these creations, there are exhibitions of an iterative nature, educational games, books and facilities such as IPHAN [The National Historic and Artistic Heritage Institute], the Brazilian Banco do Nordeste and Petrobras and the fact that one of these has been approved by the Rouanet Law [a Brazilian Law enacted to encourage the funding of cultural projects] and has even welcomed to its premises the Chancellor Emeritus of UNESCO. Thus the purpose of this article is to display the artistic products as representations of the landscape heritage which is essentially committed to historical-cultural knowledge and educational practice.

Keywords: post colonials cities, landscape heritage, design.

\section{ESTUDANDO A PAISAGEM}

Como descrever as primeiras vilas e cidades brasileiras? Quais eram os atores das cenas urbanas seiscentistas? Como chegam estas vilas e cidades aos dias de hoje e que marcas antigas permaneceram em suas formas urbanas contemporâneas?

As investigações produzidas pelo Grupo de Pesquisa Estudos da Paisagem, sediado na Faculdade de Arquitetura e Urbanismo da Universidade federal de Alagoas, buscam repertoriar manifestações arquitetônicas, urbanas e paisagísticas das primeiras vilas e cidades situadas no nordeste brasileiro, através de estudos comparativos entre espaços e tempos. A paisagem - entendida aqui como conceito que dá relevo particularmente aos processos de identificação humana e social com o espaço - abarca o gesto urbano nas suas várias dimensões. A história, entendida como matéria do presente, é convocada a mirar o futuro.

Nessa perspectiva, como ferramenta de pesquisa, o Grupo se utiliza de três condutas. A primeira relaciona-se às fontes históricas, dentre as quais se prioriza o estudo e tratamento das imagens, inclusive utilizando os meios infográficos. Certamente, seria difícil responder as questões acima indicadas e saber sobre as formas das nossas primeiras paisagens se não fosse o material iconográfico produzido no contexto da ocupação do território da colônia portuguesa na América. Especialmente o registro realizado por cosmógrafos, naturalistas e pintores europeus 
deste processo, permitindo, hoje, o acesso ao difícil conteúdo do mundo concreto e imaginário de uma sociedade distanciada por séculos.

O Nordeste da colônia, além da obra cartográfica e pictórica realizada pelos portugueses, conta-se com o extraordinário acervo de imagens produzidas pelos holandeses integrantes da comitiva de Maurício de Nassau, que desembarcaram na Capitania de Pernambuco em 1630, ali permaneceram por 24 anos.
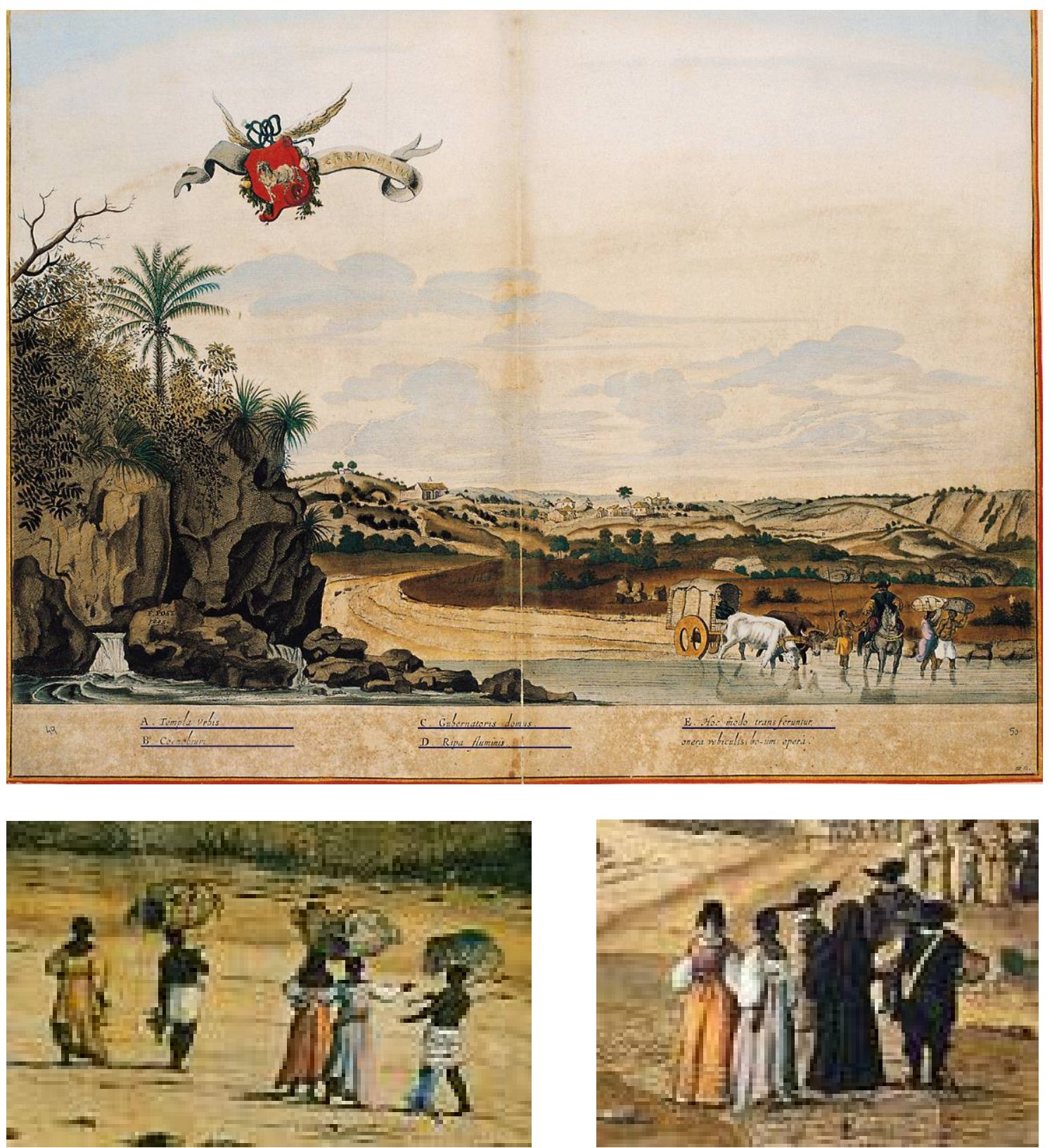

Figura 1 - Exemplo de imagens seiscentistas. Vista de Vila Formosa de Serinhaém (PE) e detalhes das vistas de Olinda e Igarassu mostrando o movimento de pessoas, elaboradas por Frans Post. Fonte: LAGO, 2006.

Essas imagens, expressivamente representadas pelas obras de Frans Post, Albert Echkout e George Marcgrave, apenas recentemente foram disponibilizadas ao público de forma mais completa através de inúmeras publicações e exposições de grande porte. Cabe citar, dentre a produção bibliográfica, a coleção Brasil-Holandês da Editora Índex, patrocinada pela Petrobrás e os catálogos que acompanharam as 
exposições intituladas "O Brasil e os Holandeses", "Frans Post", "Eckhout retorna ao Brasil", parte do catálogo da Mostra do Descobrimento, da Fundação Bienal de São Paulo e o catálogo "FRANS POST \{1612-1680\} Obra Completa" publicado pela Editora Capivara, em dezembro de 2006.

Privilegiando a análise de fontes iconográficas primárias, o Grupo trabalha partindo do confronto entre representações históricas e situações paisagísticas atuais. Dentre suas atividades situa-se a de catalogar referências da paisagem urbana, desde expressões físicas até aspectos relativos a hábitos e costumes acumulados na longa duração.

A segunda conduta metodológica seria a de investigar o próprio objeto na sua dimensão material, requerendo a realização de inúmeras viagens.

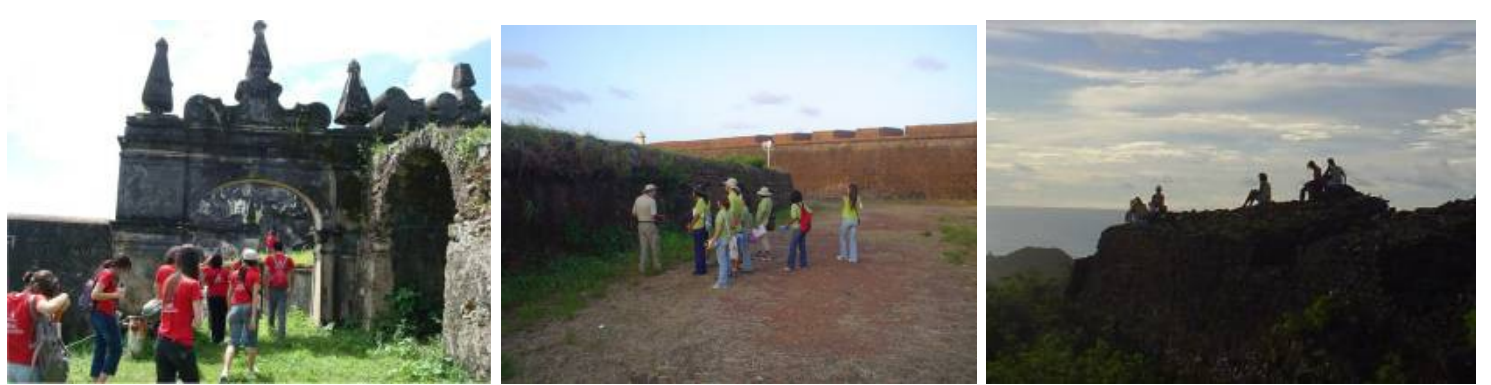

Figura 2 - Grupo em visita de campo na Bahia, no Amapá e no Arquipélago de Fernando de Noronha. Fonte: Acervo do Grupo de Pesquisa Estudos da Paisagem

A terceira busca incentivar a manifestação dos sentidos, da sensibilidade e do desejo como mecanismos de produção do conhecimento, da construção do indivíduo e do incentivo ao saber. Neste aspecto, adota-se práticas próximas ao Situacionismo de Guy Debord (1958), engaja o corpo como veículo de observação que tem o corpo com um veículo de observação. As derivas e as observações da paisagem em seu próprio ambiente físico são consideradas como processos metodológicos não apenas para revisar e averiguar os dados coletados nas fontes documentais, como também para reconhecer o lugar, tendo esse mesmo como um documento.

Seguindo esse percurso investigativo, o Grupo de Pesquisa busca, através de seus trabalhos, contribuir para os estudos urbanos comparados, tendo como ferramentas programas de manipulação gráfica. Aborda as trajetórias urbanas de um conjunto de cidades nordestinas, visando fortalecer suas propriedades patrimoniais e identitárias. Com isso, a pesquisa se coloca na condição de fornecer subsídios a ações de instituições públicas vinculadas à cultura urbana, ao turismo, ao reconhecimento do patrimônio citadino, bem como para a realização de produtos e de atividades de socialização do conhecimento através da linguagem gráfica e digital.

Fazendo parte de uma Instituição de Ensino Superior que confirma sua responsabilidade frente a Estados da Federação que conjugam indicadores de grave desigualdade social, o Grupo de Pesquisa pretende que as ações científicas desenvolvidas no seu escopo possam se somar a outras que se mobilizem para a reversão deste quadro, como as propostas pelo Plano de Ação para Ciência, Tecnologia e Inovação (PACTI). Nesse sentido, o projeto aponta para futuras ações artísticas e patrimoniais que aproximem a experiência proporcionada pelas atividades de pesquisa e de design de produtos culturais, um campo ainda novo nas searas da academia. 


\section{DE FORA PRA DENTRO, DE DENTRO PRA FORA}

Como acima mencionado, o Grupo vem trabalhando de forma interdisciplinar com o tema das temporalidades urbanas, tomando como ferramentas metodológicas principais o trabalho de campo e a análise de fontes iconográficas primárias através de processos de manipulação digital. Com o apoio de órgãos de fomento e empresas, o grupo já realizou um conjunto expressivo dos projetos relacionados a cidades brasileiras situadas no Nordeste do Brasil, colocando como questão principal o entendimento de como surgiram e se transformaram seus núcleos de mais densa base temporal.

Em princípio, tomou-se como recorte geográfico cidades situadas nos Estados da Paraíba, Pernambuco, Alagoas, Sergipe e Bahia visando compreender o que revelam os mais antigos registros iconográficos sobre o desenho urbano destas localidades, buscando contribuir no entendimento da formação da paisagem nordestina. Contudo, as contínuas idas a campo e o constante trabalho de análise da iconografia histórica demonstrou ser possível galgar uma experiência mais consistente, ampla e ao mesmo mais engajada nos processos de popularização da ciência, tendo como suporte os projetos desenvolvidos nesta linha.

Nesse processo empírico de investigação, um filtro, que inicialmente teria a função de identificar ruas e edifícios, foi revelando gestos, movimentos de coisas e pessoas, o que desestabilizou a idéia mais próxima do senso comum que vê a arquitetura enquanto matéria estática. Além disto, a experiência empírica com os objetos de estudo ampliou a noção de paisagem, mostrando, por exemplo, que as suas marcas nem sempre são tão visíveis a ponto de serem reconhecidas como memória urbana. Por vezes trata-se de um trecho de rua, de marcas na toponímia, ou uma vegetação que tem vencido o tempo, detalhes que apenas um estudo mais aprofundado revela o seu significado. Assim, o problema que se tem buscado abordar não é apenas o desaparecimento das marcas da memória urbana, mas por vezes, o desconhecimento das mesmas.

Estas centralidades urbanas que acumulam memórias se deparam com uma progressiva submissão a intenso processo de transformação urbana, seja pelo impulso ao turismo, seja pela própria força da dinâmica do tempo. Os produtos dos estudos da paisagem buscam justamente repertoriar outros sinais de densidade temporal e patrimonial, enquanto trazem outros argumentos para justificar a importância dos já reconhecidos.

As visitas e os registros audiovisuais têm se revelado como mecanismos essenciais de aproximação com os lugares. Assim, a equipe agrega entre suas funções de pesquisa, a geração de imagens, a captação de depoimentos e de sons, que servem de base para a investigação e a seguir, para o design de produtos. Nesse sentido, além dos trabalhos de pesquisa acadêmica, a intenção do Grupo volta-se também para atividades de documentação, contando com um acervo de cerca de 20 mil imagens entre registros de iconografia histórica e fontes imagéticas recentes, no geral relativas à Região Nordeste do Brasil.

Com o intuito de disponibilizar este acervo, formatado de maneira a subsidiar ações em termos de planejamento, de impulso ao turismo, de preservação do patrimônio material e imaterial, foram idealizados uma série de projetos sob a responsabilidade do Laboratório de Criação Taba-êtê que funciona como um 
desdobramento do Grupo. Suas propostas gráficas e artísticas possuem a peculiaridade de transformar as ferramentas de trabalho de pesquisa científica do Grupo - viagens e imagens - em criações que socializem o conhecimento acumulado pela pesquisa.

Portanto, valendo-se da trajetória realizada e do compartilhamento acadêmico estabelecido com outros pesquisadores, especialmente das trocas experimentadas com as próprias localidades, o Grupo tem focado as investigações nas possibilidades de operacionalização rumo à produção de conteúdos gráficos e digitais, e materiais voltados para divulgação científica do conhecimento, ao ponto em que também contribui para a educação universitária e comunitária, gerando materiais de apelo didático e com feições interativas. Dentre os resultados dessa iniciativa, situam-se os próprios relatórios de pesquisa reformatados na linguagem semelhante a de um site e disponibilizados para as agências financiadoras; livro de cunho lúdico distribuído a escolas públicas; exposições de linguagem digital; eventos itinerantes e vídeos, sejam de caráter de registro ou de divulgação, na perspectiva de despertar o interesse público pelo patrimônio paisagístico. ${ }^{1}$
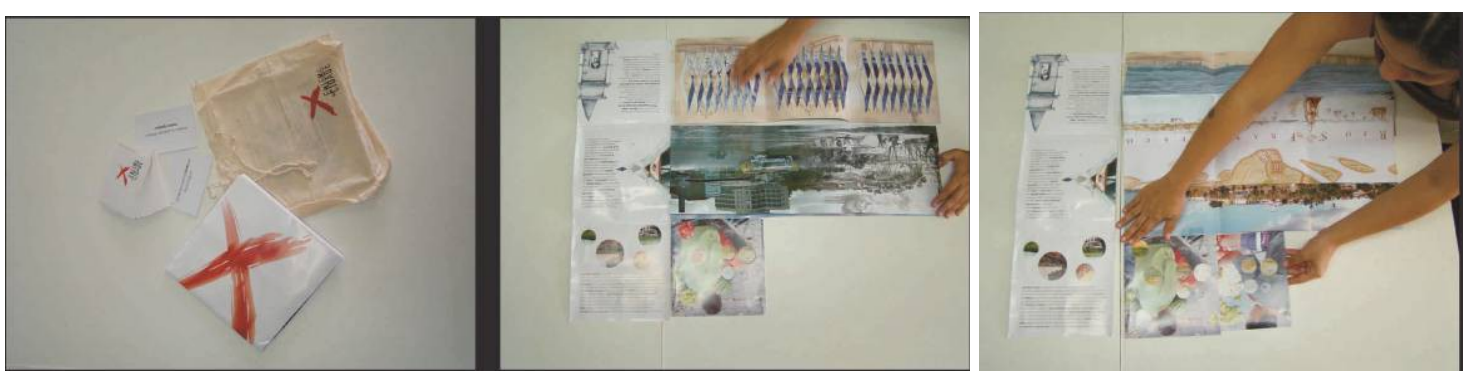

Figura 3 - Imagens do produto financiado pelo BNB (edital 2005): livro ludo-didático sobre três núcleos coloniais alagoanos, destinados ao público infantil e distribuídos em escolas e bibliotecas públicas por intermédio da Secretaria da Educação do Estado. Fonte: Grupo de Pesquisa Estudos da Paisagem/Laboratório de Criação Taba-êtê

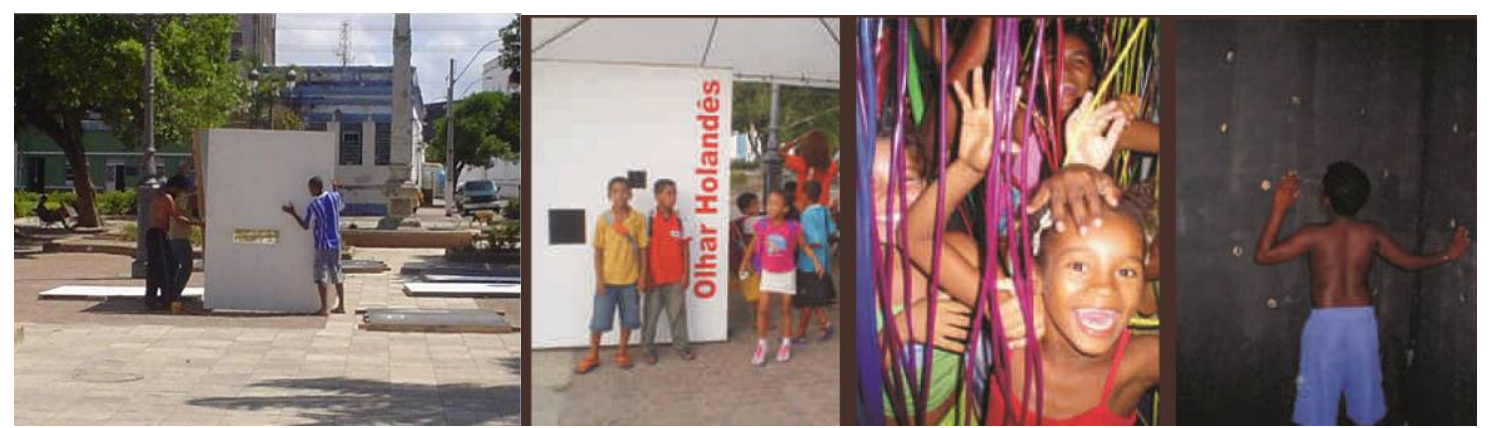

Figura 4 - Montagem da estrutura da Exposição $O$ Olhar Holandês em praça pública, e sua apropriação pelas crianças moradoras do Bairro de Jaraguá, Maceió-AL, 2005. A intenção foi trazer para a comunidade a possibilidade de acesso a imagens antigas e contemporâneas de aspectos das paisagens alagoanas. Fonte: Grupo de Pesquisa Estudos da Paisagem/Laboratório de Criação Taba-êtê

\footnotetext{
${ }^{1}$ O primeiro trabalho desenvolvido pelo Laboratório foi A Invenção da Cidade, que teve como objetivo levar a pergunta da pesquisa sobre a implantação das primeiras unidades urbanas para as comunidades, colocando também para elas o desafio de respondê-la. Composto por um conjunto de produtos culturais - um livro, um cd-rom, um objeto ludo-didático e uma exposição de caráter itinerante - foi aprovado pela Lei Rouanet de Incentivo à Cultura (processo PRONAC 013985) e recebeu a chancela da UNESCO em 2001. Não foi viabilizado devido às dificuldades com a captação de recursos.
} 

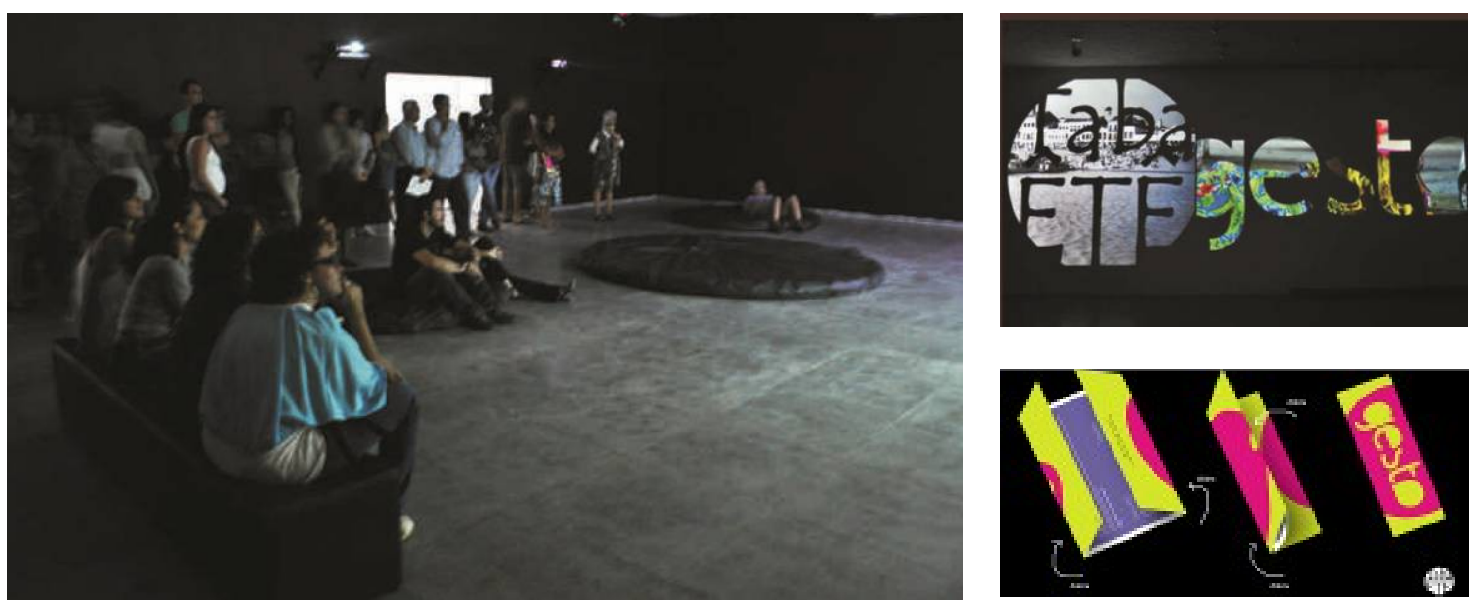

Figura 5 - Imagens da Exposição Gesto e seu folder de divulgação. Foi selecionada pelo edital nacional 2010 da Pinacoteca da UFAL. Constitui de imagens e sons colhidos das inúmeras comunidades visitadas pelo Grupo e misturados às vozes de membros da Faculdade de Arquitetura que foram manipuladas seguindo a idéia de marcos identitários. Fonte: Grupo de Pesquisa Estudos da Paisagem/Laboratório de Criação Taba-êtê

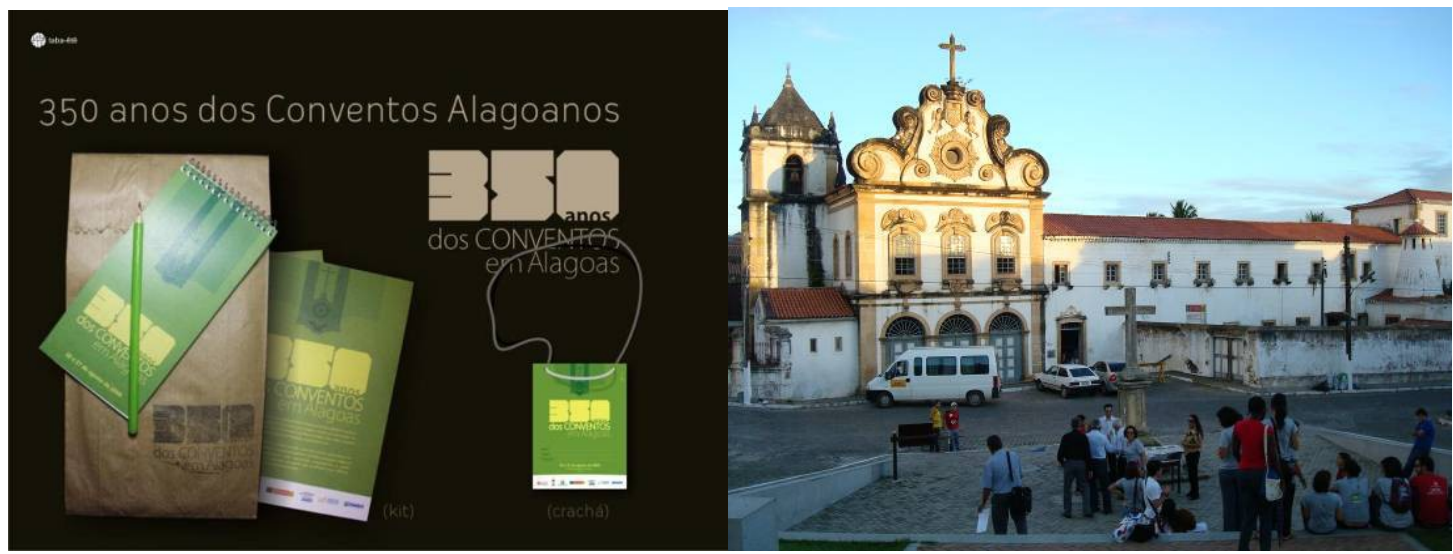

Figura 6 - Imagem do material gráfico do evento itinerante e comemorativo dos 350 anos do Convento de Santa Maria dos Anjos na cidade de Penedo-AL, e do público do adro do edifício. Fonte: Grupo de Pesquisa Estudos da Paisagem/Laboratório de Criação Taba-êtê

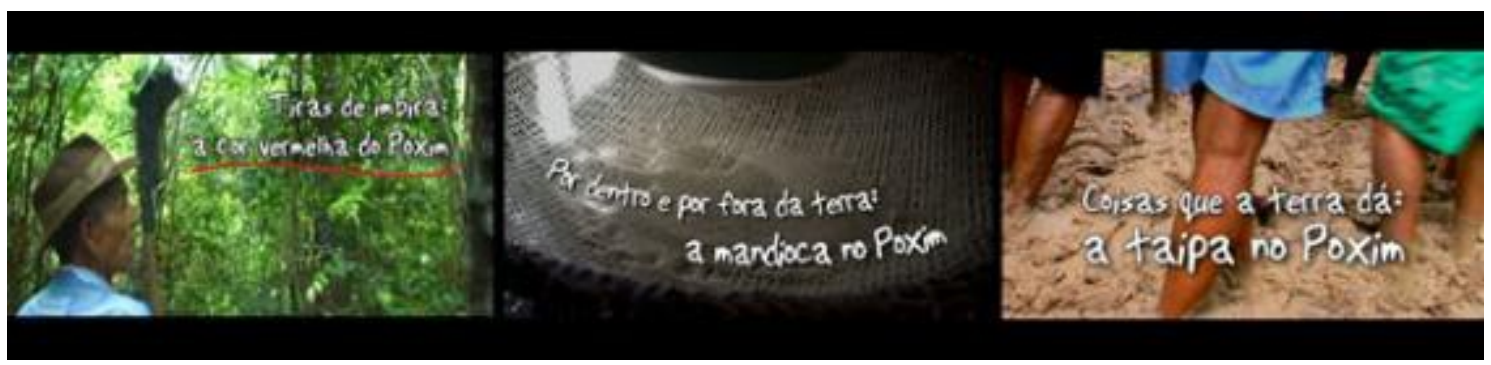

Figura 7 - Imagens da face de abertura dos vídeos de registro das expressões imateriais cotidianas manifestadas em comunidades alagoanas. Produto do projeto Modos de construir, modos de alimentar, memórias da paisagem Caeté das Alagoas, financiado pelo Instituto do Patrimônio Histórico e Artístico Nacional (IPHAN, edital 01/2005), consistiu na produção de 3 registros audiovisuais de duração de cerca de 10 minutos cada. Os vídeos foram exibidos em circuito restrito por se tratar de material acadêmico, mas foram disponibilizados para serem exibidos nos seguintes 
eventos: Amostra Arte na Casa, Amostra Questões Urbanas promovida pelo Grupo e pelo SESC. Fonte: Grupo de Pesquisa Estudos da Paisagem/Laboratório de Criação Taba-êtê
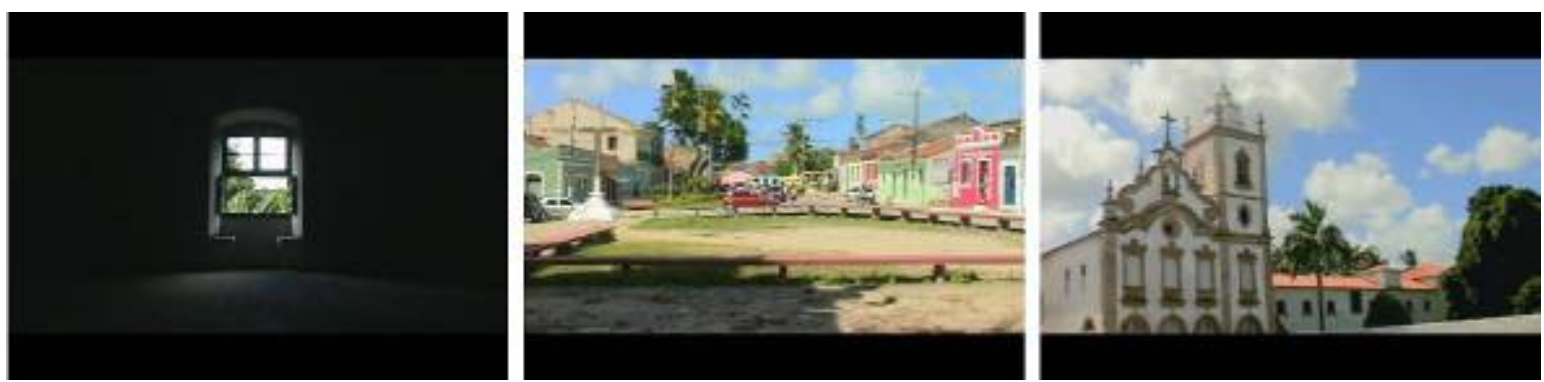

Figura 8 - Imagens do vídeo televisivo, com a seguinte narração: “Em Marechal Deodoro, o Convento de Santa Maria Madalena é patrimônio nacional. 0 monumento só tem sentido se encontra abrigo no afeto das pessoas. Reconheça seu patrimônio". Produto financiado pela PETROBRÁs. Fonte: Grupo de Pesquisa Estudos da Paisagem/Laboratório de Criação Taba-êtê

\section{A PESQUISA ACADÊMICA E O DESIGN SOCIAL}

Os produtos elaborados pelo Laboratório de Criação Taba-êtê atentam para a possibilidade de participação do público que, talvez, sinta necessidade de acessar outros meios para poder construir o seu conteúdo. A ideia é que, entre imagens e palavras, existam dicas, pistas sobre cenas cotidianas que aparentemente são desprovidas de valor, mas que constituem o próprio patrimônio local.

Sendo assim, esses produtos culturais baseiam-se nos esforços de investigação realizados por um grupo de pesquisa que pretende divulgar os resultados obtidos não apenas no circuito acadêmico, mas retornar às cidades e seus habitantes esses conteúdos em formato de produtos comprometidos com a educação básica e com o desenvolvimento da cidadania, buscando despertar o interesse pelo conhecimento e valorização do patrimônio histórico nacional, com repercussões no sentido de pertencimento e de auto-referência dos próprios cidadãos.

\section{REFERÊNCIAS}

BACHELARD, Gaston. A poética do espaço. In: Os Pensadores. Vol. XXXVIII. São Paulo: Agril Cultural, 1974.

BENJAMIN, Walter. Rua de mão única. São Paulo: Editora Brasiliense, 1994.

DUBY, G. O historiador, hoje. In: LE GOFF, J. (Org.). História e nova história. Editorial Teorema: Lisboa, 1986. p. 7-20.

GINZBURG, Carlo. Mitos, Emblemas e Sinais. São Paulo: Cia das Letras, 1989.

JACQUES, Paola Berenstein. Apologia da deriva. Rio de Janeiro: Casa da Palavra, 2003.

Estética da ginga - a estética das favelas a partir da obra de Hélio Oiticica.

Rio de Janeiro: Casa da Palavra, 2001.

JEUDY, Henri Pierre \& JACQUES, Paola Berenstein (Org.). Corpos e cenários urbanos. Salvador: UFBA, 2006. 
LAGO, Beatriz e Pedro Corrêa do. FRANS POST \{1612-1680\} Obra Completa. Rio de Janeiro: Capivara, 2006.

SILVA, Maria Angélica da \& AZEVEDO, Anna Victória Wanderley Silva de. Breves linhas sobre o corpo e a arquitetura. In: Revista Vivência. Natal: UFRN/CCHLA. N. 37, 105122, jan./jun., 2011.

SILVA, Maria Angélica da \& APRIGIO, Érica. Arquitetura que pulsa. ANAIS eletrônico do 5o Projetar. Belo Horizonte, 2011. CD ROM 